\title{
Biological Pathotyping of Newcastle Disease Viruses in Sudan 2008-2013
}

\section{Egbal Sidahmed Abdelrahim Bilal, Iman Mohammed Elnasri, Aymen Mohamed Alhassan, Khalda Abdelaziz Khalifa, Jedddha Ibrahim Elhag, and Selma Osman Ahmed}

\author{
Veterinary Research Institute, P.O. Box 8067, Khartoum, Sudan \\ Correspondence should be addressed to Egbal SidAhmed Abdelrahim Bilal; igbalsss@hotmail.com
}

Received 30 June 2014; Revised 28 October 2014; Accepted 28 October 2014; Published 26 November 2014

Academic Editor: Nora Mestorino

Copyright (C) 2014 Egbal Sidahmed Abdelrahim Bilal et al. This is an open access article distributed under the Creative Commons Attribution License, which permits unrestricted use, distribution, and reproduction in any medium, provided the original work is properly cited.

\begin{abstract}
The biological properties and pathogenicity of seven Newcastle disease virus field isolates were studied. These isolates were recovered from different outbreaks in Sudan (5 from chickens and 2 from pigeons) during 2008-2013. Based on intracerebral pathogenicity index, four NDV isolates were characterized as velogenic (their ICPI ranged 2.0-1.6) and three isolates were characterized as mesogenic (ICPI ranged 1.2-1.3). The mean death time for all isolates ranged from 54 to 76.8 hours. The elution time of the viruses from chicken erythrocytes and the ability to haemagglutinate mammalian red blood cells differed considerably in their reactions.
\end{abstract}

\section{Introduction}

Newcastle disease (ND) is still considered as an economically important disease which is highly contagious infection for many avian species. ND is caused by virulent strains of avian paramyxovirus type 1 (APMV-1) of the genus Avulavirus belonging to the family Paramyxoviridae [1]. According to the World Organization for Animal Health (OIE, 2012), ND is an OIE notifiable disease when it meets certain criteria of virulence.

Newcastle disease affects a wide range of domestic and wild avian species; however, the severity of the disease varies greatly, spanning from peracute disease with almost $100 \%$ mortality to subclinical disease with no lesions. Such variability makes it impossible to pinpoint ND as a single clinicopathologic entity [2]. Based on severity of clinical disease, the strains of NDV were originally classified into 3 groups based on their virulence such as lentogenic, mesogenic, and velogenic. Lentogenic strains, especially in adult chickens, may cause minimal or no clinical signs. However, the disease produced by mesogenic strains may cause mortality that can reach $25 \%$ and those by in velogenic strains may reach up to $100 \%$ [3] Differences in virulence of the virus occur during any disease outbreak, so determining virulence is essential for the effective control of the disease.
ND was first reported in Sudan in 1951 [4] and still constituted a major problem facing the poultry industry. Newcastle disease virus (NDV) exhibits a wide range of pathogenicity and virulence. Assessment of the virulence of NDV is necessary in order to limit the outbreaks and to minimize their impact. So the aim of this study was to evaluate the pathogenicity of some NDV field strains isolated 2008-2013.

\section{Materials and Methods}

2.1. Viruses. Seven NDV viruses were isolated from different hosts, including chickens (layers and broilers) and pigeons from several regions in Sudan during 2008 to 2013 from cases submitted for diagnosis to the Department of Avian Diseases and Diagnosis, Veterinary Research Institute, Khartoum, Sudan. The information concerning the origin of virus outbreaks, the year of isolation, breed, type, and age of birds involved is presented in Table 1. Mortality during the outbreak varied from $90 \%$ in young chickens to less than $2 \%$ in hens; however, egg production dropped from 90 to $40 \%$. Clinical signs of the disease were similar among most poultry farms including dyspnea, nervous, respiratory signs, diarrhea, and cyanosis of the combs. 
TABLE 1: The location of NDV outbreaks, year of isolation, type, breed, and age of birds involved.

\begin{tabular}{lcccccc}
\hline Virus strain & Abbreviation & Location of outbreak & Year of isolation & Host & Type/breed of bird & Age \\
\hline Layer/Nyala/08 & LNy/08 & Nyala & 2008 & Chicken & layer/lohman & 18 weeks \\
Layer/Nyala/09 & LNy/09 & Nyala & 2009 & Chicken & layer/Bovans & 15 months \\
Pigeon/Kamlen/09 & Pkam/09 & Kamleen & 2009 & Pigeon & - & Adult \\
Pigeon/Medni/010 & Pmed/010 & Medani & 2010 & Pigeon & - & Adult \\
Broiler/Halfaya/011 & Bhalf/011 & Halfaya & 2011 & Chicken & Broiler/Ross & 30 days \\
Broiler/Soba/2013 & Bso/013 & Soba & 2013 & Chicken & Broiler/Cobb & 6 days \\
Layer/Kabashi/2013 & Lkab/013 & Kabashi & 2013 & Chicken & layer/Hyline & 6 months \\
\hline
\end{tabular}

2.2. Chicks and Embryonated Egg. Nine-to-eleven-day-old embryonated eggs (Bovan) and chicks (cockerels) were provided by the Coral Farm Hatcheries. Before use the chicks were checked for NDV antibodies and were found negative.

2.3. Virus Isolation and Identification. Filtrates of processed tissues from the trachea, lung, brain, spleen, and cecal tonsils from different hosts were used to inoculate 9-11-day embryonated eggs for virus isolation via allantoic route and the NDV was identified by means of HA and HI test using standards procedures [1]. Virus stocks grown in allantoic fluids were stored at $-20^{\circ} \mathrm{C}$ until being used.

\subsection{Haemagglutination of Chicken and Mammalian Erythro-} cytes. The test was performed in V-shaped microtitre plates. Volumes of $25 \mu \mathrm{L}$ of PBS were placed in each well of the plate followed by $25 \mu \mathrm{L}$ of allantoic fluid of virus isolate in each well in the first row. After 2 fold dilutions were carried out in subsequent rows, $25 \mu \mathrm{L}$ of $1 \%$ suspension of chickens, cattle, sheep, and equine RBCs was added to each well. After 30 minute of incubation at room temperature, the reciprocal of the highest dilution that produced positive $\mathrm{HA}$ was considered as positive virus titre.

2.5. Haemagglutination Elution Test. The test was done following the procedures described previously $[5,6]$. A standard HA test was performed with chicken RBCs in WHO haemagglutination plates using $500 \mu \mathrm{L}$ volumes. The test was incubated at $4^{\circ} \mathrm{C}$ for 1 hour before the HA titre was calculated. After gentle mixing and further incubation, the HA titre was also recorded at 24 and 30 hours.

\subsection{Biological Pathogenicity Assessment}

2.6.1. Mean Death Time of the Minimum Lethal Dose $(M D T / M L D)$. MDT was performed in 9-10-day-old embryonated egg. Serial tenfold dilutions of allantoic fluid (AF) of each virus isolate were prepared and $0.1 \mathrm{~mL}$ of the dilutions $\left(10^{-5}, 10^{-8}\right.$, and $\left.10^{-9}\right)$ was inoculated into the allantoic cavity using 5 eggs per dilution. The highest dilution at which all embryos died soon was considered as mean lethal dose (MLD) and the MDT/MLD was calculated as described [7].

2.6.2. Intracerebral Pathogenicity Index (ICPI) Assessment. Pathogenicity of NDV isolates was assessed by using the standard intracerebral pathogenicity index (ICPI) test. Briefly,
TABle 2: Haemagglutination pattern of the NDV field isolates to chicken, equine, sheep, and bovine RBCs.

\begin{tabular}{lcccc}
\hline NDV isolate & $\begin{array}{c}\text { Chicken } \\
\text { RBCs }\end{array}$ & $\begin{array}{c}\text { Equine } \\
\text { RBCs }\end{array}$ & $\begin{array}{c}\text { Sheep } \\
\text { RBCs }\end{array}$ & $\begin{array}{c}\text { Bovine } \\
\text { RBCs }\end{array}$ \\
\hline LNy/08 & $6 \log _{2}$ & 0 & 0 & 0 \\
LNy/09 & $10 \log _{2}$ & $5 \log _{2}$ & 0 & 0 \\
Pkam/09 & $8 \log _{2}$ & $4 \log _{2}$ & $8 \log _{2}$ & $4 \log _{2}$ \\
Pmed/010 & $5 \log _{2}$ & 0 & 0 & 0 \\
Bhalf/011 & $10 \log _{2}$ & 0 & 0 & 0 \\
Bso/013 & $7 \log _{2}$ & $4 \log _{2}$ & $6 \log _{2}$ & $3 \log _{2}$ \\
Lkab/013 & $7 \log _{2}$ & $3 \log _{2}$ & $3 \log _{2}$ & $2 \log _{2}$ \\
\hline
\end{tabular}

ten-one-day-old chicks were inoculated intracerebrally with $0.1 \mathrm{~mL}$ of a $1: 10$ dilution of allantoic fluid of each virus isolate. Ten chicks were kept as uninoculated control. All chicks were monitored during an eight-day observation period and scored as normal (0), sick or paralyzed (1), and dead (2). Total scores were determined, and the mean daily score was calculated to obtain the ICPI as described [8].

\section{Results}

3.1. Virus Isolation. Following inoculation of embryonated chicken eggs with suspensions from organs of diseased birds, embryo died 2-3 days after inoculation for the Pmed/010, Bhalf/011, Bso/013, and Lkab/013 and 4-5 days for LNy/08, $\mathrm{LNy} / 09$, and Pkam/09 NDV isolates.

The harvested allantoic fluids from dead eggs agglutinated red blood cells of chickens and this agglutination was inhibited by addition of specific NDV antiserum.

3.2. Haemagglutination of Chicken and Mammalian Erythrocytes. Table 2 shows the HA pattern of field NDV isolates. The Pkam/09, Bso/013, and Lkab/013 agglutinated equine, sheep, and bovine RBCs while LNy/09 agglutinated only the equine RBCs. The LNy/08, Pmed/010, and Bhalf/011 did not agglutinate any of the mammalian species RBCs.

3.3. Haemagglutination Elution Test. The haemagglutination elution of the NDV field isolate recorded after 1, 24, and 30 hours was illustrated in Table 3. There is a difference in HA titre recorded in 24 and 30 hours of all isolates. 
TABLE 3: Haemagglutination elution of the NDV field isolates.

\begin{tabular}{lccc}
\hline NDV isolate & \multicolumn{3}{c}{ HA titre } \\
& 1 hour & 24 hours & 30 hours \\
\hline LNy/08 & $6 \log _{2}$ & $5 \log _{2}$ & 0 \\
77 & $6 \log _{2}$ & $3 \log _{2}$ & 0 \\
LNy/09 & $7 \log _{2}$ & $4 \log _{2}$ & 0 \\
Pkam/09 & $6 \log _{2}$ & $4 \log _{2}$ & 0 \\
Pmed/010 & $3 \log _{2}$ & $1 \log _{2}$ & 0 \\
Bhalf/011 & $8 \log _{2}$ & $5 \log _{2}$ & 0 \\
Bso/013 & $6 \log _{2}$ & $4 \log _{2}$ & 0 \\
Lkab/013 & $6 \log _{2}$ & $5 \log _{2}$ & 0 \\
\hline
\end{tabular}

TABLE 4: The ICPI values and the MDT produced by the NDV isolates.

\begin{tabular}{lccc}
\hline NDV isolate & MTD $^{*}$ (hours) & ICPI & $\begin{array}{c}\text { Pathotype based } \\
\text { on ICPI** }\end{array}$ \\
\hline LNy/08 & NT & 1.3 & Mesogenic \\
LNy/09 & 76.8 & 1.2 & Mesogenic \\
Pkam/09 & 62.4 & 1.3 & Mesogenic \\
Pmed/010 & 48 & 1.8 & Velogenic \\
Bhalf/011 & 51 & 2.0 & Velogenic \\
Bso/013 & 57 & 1.6 & Velogenic \\
Lkab/013 & 54 & 1.6 & Velogenic \\
\hline
\end{tabular}

${ }^{*}$ MDT: mean death time, measured in hours to death; ${ }^{* *}$ ICPI: intracerebral pathogenicity index, based on an average score of clinical signs over time.

\subsection{Pathogenicity Test}

3.4.1. Mean Death Time of the Minimum Lethal Dose (MDT/ $M L D)$. The MDT of the NDV isolates was presented in Table 4. MDT ranged from 54-76.8 hours for all isolates.

The ICPI of the LNy/08, LNy/09, and Pkam/09 was 1.3 , 1.2 , and 1.3 which can be classified as mesogenic strains. The ICPI of the Pmed/010, Bhalf/011, Bso/013, and Lkab/013 was $1.8,2.0,1.6$, and 1.6, respectively, which classified as velogenic NDV strains.

\section{Discussion}

Newcastle disease (ND) is a serious and commonly fatal viral poultry disease, which is present all over the world. Viral characterization using the pathogenicity test or molecular typing is essential, as the importance and impact of a given NDV isolate are directly related to its virulence.

In the present study NDV isolates were from outbreaks of different locations and five isolates were recovered from chickens while two were from pigeons.

The ability of NDV to agglutinate red blood cells (RBCs) is due to the binding of the $\mathrm{HN}$ protein to receptors on the surface of the RBCs. Chicken RBCs are usually used in HA tests but NDV will cause agglutination of all amphibian, reptilian, and avian cells. The ability of NDV strains to agglutinate cattle, goat, sheep, swine, and horse RBCs varied among various strains [9]. Ibu et al. (2009) [10] applied the haemagglutinability tests using mammalian erythrocytes as a tool for strain differentiation. Here among the field isolates tested, three isolates agglutinated mammalian RBCs. It is noticed that there is a difference in hemagglutination patterns which could not be correlated to the virulence of the NDV isolates. This result was similar to previous research [11] and disagrees with the suggestion of others [12] that the pattern of agglutination of some NDV strains may be related to the degree of virulence that more virulent strains appear to show less agglutinability of certain mammalian red blood cells than the less virulent ones.

Elution time could form a basis for rough characterization of isolates of Newcastle disease virus $[5,6,13,14]$. The NDV isolates used in this study were slow HA eluters. Their elution reactions appear not to be correlated to their virulence.

Previously no relationship was found between haemagglutination elution patterns and other properties of the same strain $[5,6]$.

The in vivo assessment of virus virulence is based on the ICPI test, which is considered as the most sensitive and widely used test for measuring virulence [2]. In the present study, based on ICPI, the results indicated that four NDV isolates had virulent strain characteristics and other three have mesogenic characteristics. It was noticed that there was a mismatch in the indices of the MDT of the isolates. Previously a mismatch in the MDT and the ICPI values was observed [15].

\section{Conflict of Interests}

The authors declare that there is no conflict of interests regarding the publication of this paper.

\section{References}

[1] OIE, "Manual of Diagnostic Tests and Vaccines for Terrestial Animal," 2012, http://www.oie.int/eng/normes/manual.

[2] G. Cattoli, L. Susta, C. Terregino, and C. Brown, "Newcastle disease: a review of field recognition and current methods of laboratory detection," Journal of Veterinary Diagnostic Investigation, vol. 23, no. 4, pp. 637-656, 2011.

[3] M. C. Marín, P. Villegas, J. D. Bennett, and B. S. Seal, "Virus characterization and sequence of the fusion protein gene cleavage site of recent Newcastle disease virus field isolates from the southeastern United States and Puerto Rico," Avian Diseases, vol. 40, no. 2, pp. 382-390, 1996.

[4] Anon, "Annual report of of the Sudan Veterinary services," 1951.

[5] J. Spalatin, R. P. Hanson, and P. D. Beard, "The hemagglutination-elution pattern as a marker in characterizing Newcastle disease virus," Avian Diseases, vol. 14, no. 3, pp. 542-549, 1970.

[6] M. C. Ezeibe and E. T. Ndip, "Red blood cell elution time of strains of Newcastle disease virus," Journal of Veterinary Science, vol. 6, no. 4, pp. 287-288, 2005.

[7] R. P. Hanson and C. A. Brandy, "Identification of vaccine strains of Newcastle disease virus," Science, vol. 122, no. 3160, pp. 156157, 1955.

[8] C. Terregino and I. Capua, "Conventional diagnosis of Newcastle disease virus infections," in Avian Influenza and Newcastle Disease. A Field and Laboratory Manual, I. Capua and D. J. Alexander, Eds., pp. 123-126, Springer, Milan, Italy, 2009. 
[9] D. J. Alexander and R. E. Gough, "Newcastle disease other avian paramyxoviruses, and avian pneumovirus infection," in Diseases of Poultry, Y. M. Saif, H. J. Barnes, A. M. Fadly, J. R. Glisson, L. R. McDougald, and D. E. Swayne, Eds., pp. 6399, Iowa State University Press, Ames, Iowa, USA, 11th edition, 2003.

[10] J. O. Ibu, J. O. A. Okoye, J. F. Antiabong, G. A. Yabi, and B. S. Oladele, "Haemagglutinability of mammalian erythrocytes by newcastle disease virus strains isolated from central Nigeria," Archives of Veterinary Science, vol. 14, no. 1, pp. 57-62, 2009.

[11] H. S. Kianizade, H. M. A. Ideris, S. Shahrabadi et al., "Biological and Molecular characterization of Newcastle disease virus Isolated from Iran," Archive Razi Institute, vol. 50, pp. 1-10, 1999.

[12] E. S. Haruna, D. Shamaki, G. O. Echeonwu, K. A. Majiyagbe, Y. Shuaibu, and D. R. Du, "A natural outbreak of Newcastle disease in guinea-fowl (Numida meleagris galeata) in Nigeria," Revue Scientifique et Technique, vol. 12, no. 3, pp. 887-893, 1993.

[13] M. C. O. Ezeibe and E. T. Ndip, "Red blood cell elution time of strains of Newcastle disease virus," Journal of Veterinary Science, vol. 6, no. 4, pp. 287-288, 2005.

[14] B. S. Seal, D. J. King, and H. S. Sellers, "The avian response to Newcastle disease virus," Developmental and Comparative Immunology, vol. 24, no. 2-3, pp. 257-268, 2000.

[15] J. E. Pearson, D. A. Senne, D. J. Alexander, W. D. Taylor, L. A. Peterson, and P. H. Russell, "Characterization of Newcastle disease virus (avian paramyxovirus-1) isolated from pigeons.," Avian Diseases, vol. 31, no. 1, pp. 105-111, 1987. 

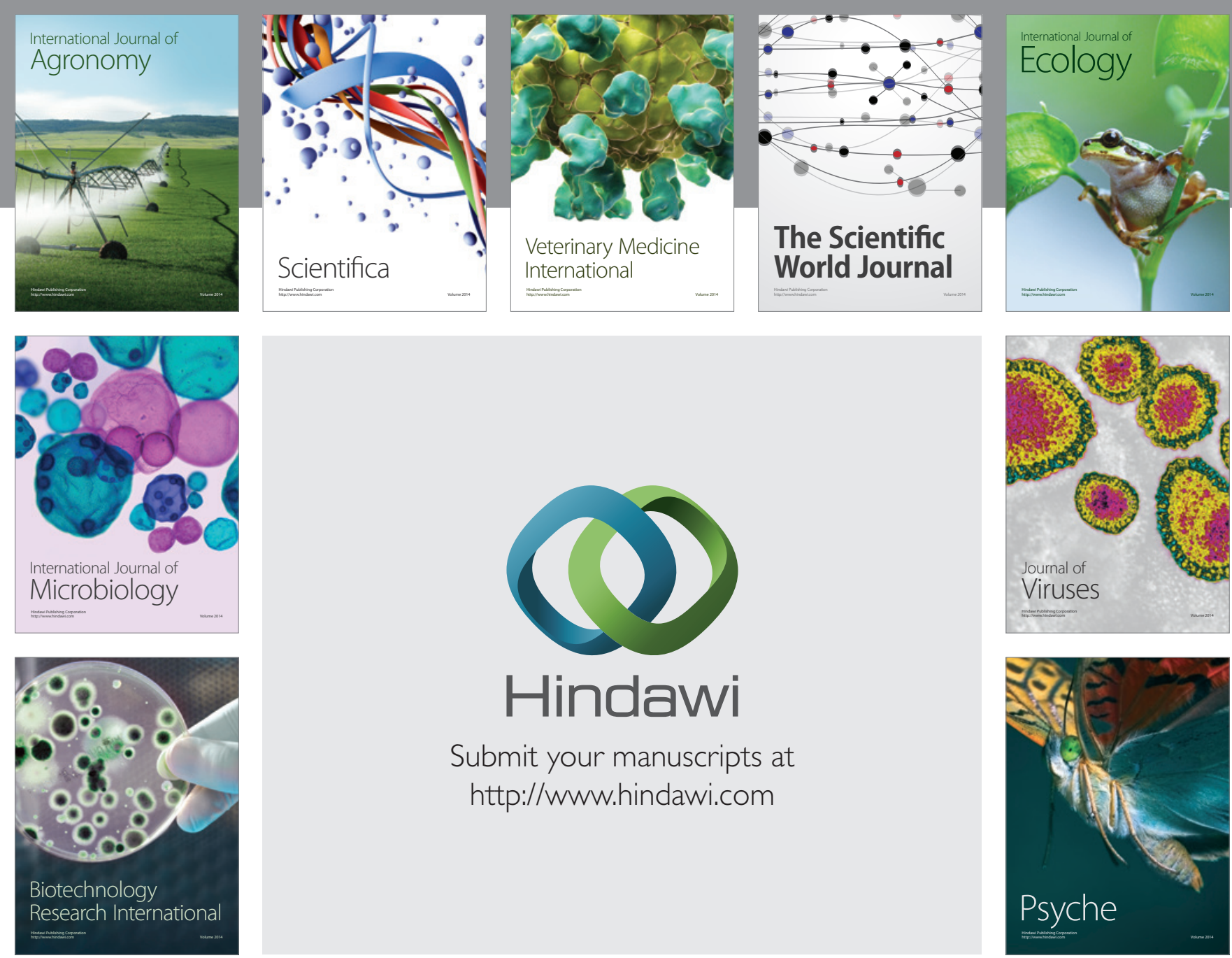

Submit your manuscripts at http://www.hindawi.com
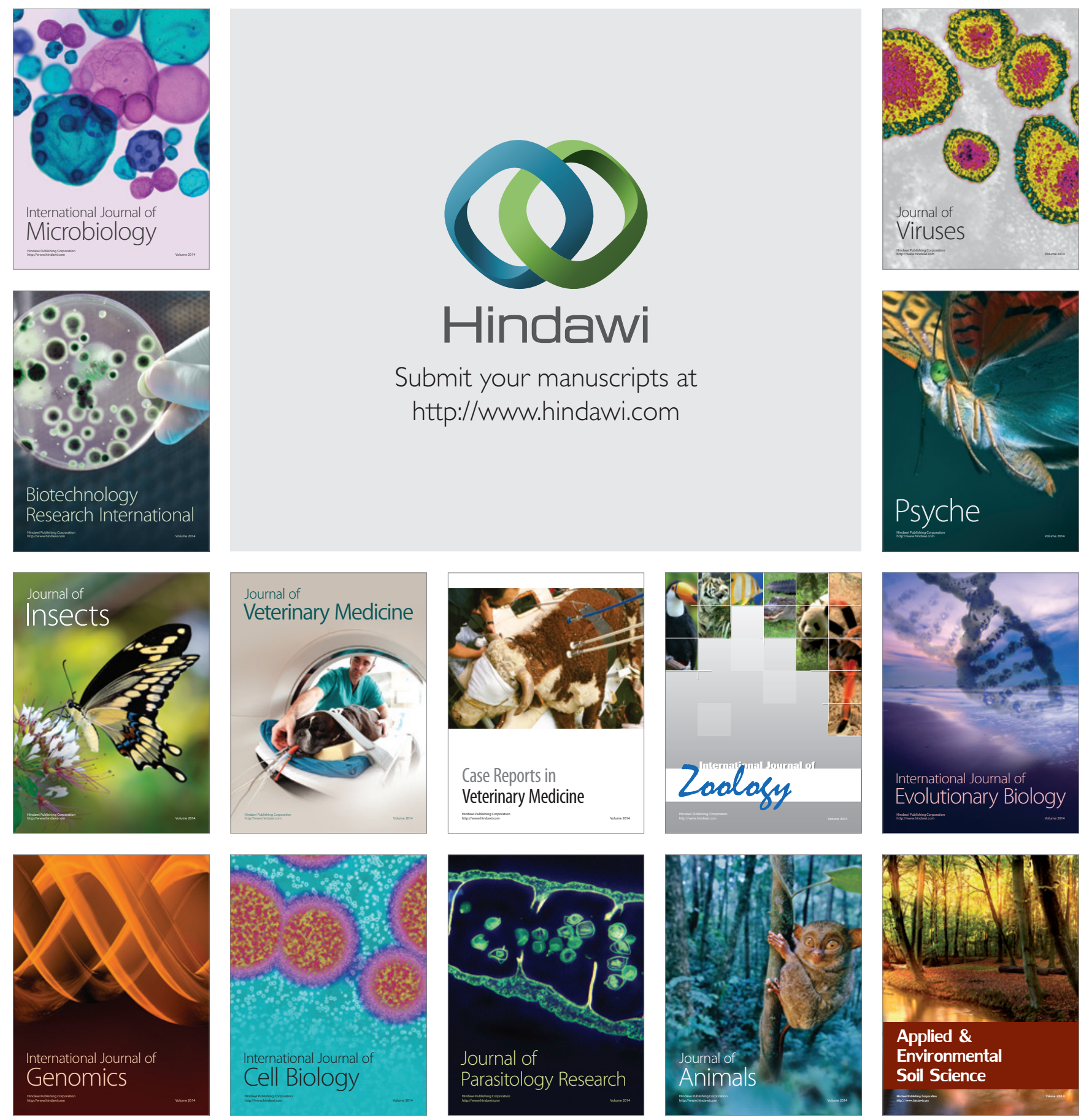